\title{
EL PARTIDO IGNACIANO: ESTRUCTURACIÓN EN EL EXILIOY Y SUPERVIVENCIA TRAS LA MUERTE DEL PATRIARCA IGNACIO I
}

\author{
The Ignatian party: organization in the exile and survival after the death of the patriarch Ignatius I
}

\author{
Óscar PRIETO DOMÍNGUEZ \\ Universidad de Valladolid \\ E-mail: praxo@yahoo.es
}

Fecha de recepción: 19-01-2010

Fecha de aceptación: 29-01-2010

RESUMEN: La deposición del patriarca Ignacio I el 23 de noviembre de 858 y su posterior exilio sumieron a la Iglesia Bizantina en la primera de las grandes crisis post-iconoclastas que habría de conocer. La consagración de Focio como su sustituto el día de Navidad del año 858 lejos de solventar el malestar creado en el seno de la cristiandad de Oriente radicalizó las posiciones de clérigos, hegúmenos y metropolitas dando origen a la disputa conocida como querella fociana. Este conflicto que marcó la segunda mitad del siglo IX bizantino se vio acentuado con el destierro y excomunión de Focio y la restauración de Ignacio (867-877) a la que siguió un segundo patriarcado de Focio (877-886). La presente comunicación pretende analizar la estructuración del partido ignaciano durante los difíciles años en los que carecieron de su líder y el modo en el que su causa sobrevivió tras la muerte de Ignacio, toda vez que Focio ejercía su ministerio sin tener que lidiar ya con ningún grupo disidente. Para ello nos centraremos principalmente en una fuente que hasta ahora ha pasado inadvertida y cuyo testimonio resulta tremendamente elocuente: el epistolario del patriarca Focio.

Palabras Clave: patriarca Ignacio I, patriarca Focio, Historia de la Iglesia Bizantina, querella fociana

ABSTRACT: The deposition of the patriarch Ignatius I on 23 November of 858 and his later exile plunged the Byzantine Church into the first one of the post-Iconoclast crises that she should know. The consecration of Photius like his substitute the day of Christmas 
of the year 858 did not drive away the discomfort created in the bosom of the East Christianity, but toughened the positions of clergymen, hegoumenoi and archbishops originating the dispute known as the Photian Schism. This conflict marked the second half of the Byzantine 9th century and was accentuated by Photius' exile and excommunication, by the restoration of Ignacio (867-877) and by Photius' second patriarchate (877-886). The present work aimes to analyze the structure of the Ignatian party during the difficult years when his leader was missing and the way in which their cause survived after Ignatius' death (when Photius exercised his ministry without opponents). For it we are going to focus principally on a source that has gone unnoticed until now but which testimony is greatly eloquent: patriarch Photius' collection of Epistles.

Keywords: Patriarch Ignatius I, Patriarch Photius, History of the Byzantine Church, Photian Schism

Corría el 14 de junio del año 847 cuando el patriarca Metodio -el restaurador del culto a los iconos- entregó su alma al Redentor. Dejaba tras de sí una Iglesia convulsa que, tras la obligada unión de fuerzas para combatir la herejía iconoclasta, redescubría fuertes disensiones en su fuero interno, como demuestra la excomunión masiva de los monjes del monasterio constantinopolitano de Estudio ${ }^{1}$.

Fruto de los desencuentros fue la falta de un candidato claro a sustituirle al frente de la cristiandad de Oriente. El nombre del arzobispo de Siracusa Gregorio Asbestas fue uno de los que sonó con más fuerza. Contemporáneo del difunto patriarca, su admiración por él era bien conocida, ya que a todas luces había llegado a convertirse en su biógrafo oficial ${ }^{2}$, y su posible elección se vislumbraba como continuista. Sin embargo, la ausencia de una clara mayoría dio pie a que la emperatriz Teodora diese un puñetazo sobre la mesa e impusiese a un hombre de su elección: Ignacio.

De acuerdo con Dvornik, la consagración como patriarca de este monje, hijo eunuco del emperador Miguel I Rangabé (811-813), satisfacía al sector eclesiástico más fanático, el de los zelotes, ya que como monje estaba muy cercano a su visión del culto y a entender como necesaria la persecución contundente de los partidarios de la iconoclastia ${ }^{3}$. Sin embargo, de acuerdo con V. Grumel y P. Karlin-Hayter el verdadero representante del partido más severo con los iconoclastas había sido Metodio, por lo que la elección de Ignacio correspondía a un intento de congraciarse con los viejos partidarios del rechazo a las imágenes ${ }^{4}$.

El nuevo patriarca no esperó para dejar patente el sectarismo con el que pensaba ejercer su ministerio y el mismo día de su entronación prohibió a Gregorio Asbestas asistir a la ceremonia, lo que irritó al arzobispo y a sus partidarios que lanzaron al suelo las velas que llevaban y le espetaron que la 
Iglesia había sido confiada a un lobo en vez de a un pastor (Vita Ignatii 512). Poco después, Ignacio hacía que un sínodo anatematizara y excomulgara a Gregorio y a sus simpatizantes, que apelaron a los papas León IV (847-855) y Benedicto III (855-858), dando pie al primer cisma iconódulo de la Iglesia recién reunificada ${ }^{5}$.

El cisma ya se había confirmado. Los estuditas fueron llamados del exilio y dentro de la corte comenzaron a fraguarse conjuras, en las que tomó parte muy activamente el más poderoso de los funcionarios imperiales, el protoasecreta Focio, espoleado en buena medida por Gregorio Asbestas.

El primer patriarcado de Ignacio (847-858) finaliza por un altercado político que terminará por sentar en el trono patriarcal a Focio. Miguel III dio un golpe de Estado que privó a su madre de continuar ostentando el poder imperial en 856 . El logoteta del dromo Teoctisto, probablemente tío de Teodora, fue sustituido por el hombre de confianza del nuevo emperador: su tío Bardas, que, como él, había sido víctima de la regencia organizada por Teodora y Teoctisto.

El día de Epifanía de 858, Bardas trasgredió la orden patriarcal y asistió a la liturgia, ante lo cual Ignacio reaccionó negándole la comunión. La respuesta del césar fue culpar a Teodora y pedir al patriarca que la tonsurara, a

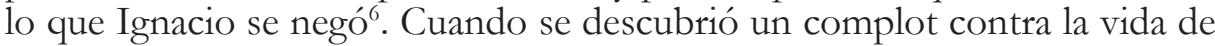
Bardas, el patriarca fue el primero en caer: fue depuesto y exiliado en la isla de Terebinto el 23 de noviembre de 858 .

En realidad, la inflexibilidad del patriarca Ignacio hacia el nuevo gobierno de Miguel III y Bardas había sido hábilmente explotada por sus opositores, que fomentaron una actitud contestataria que terminó por comprometerlo y costarle el cargo. En este sentido, su propio biógrafo Nicetas Paflagón permite observar que la jerarquía eclesiástica veía con buenos ojos la posible abdicación de Ignacio por el bien de la Iglesia. La insistencia de obispos y autoridades imperiales llevó a Ignacio a invitar a sus partidarios más acérrimos a elegir un nuevo patriarca ${ }^{7}$.

El candidato que más convencía a todas las partes fue Focio, que todavía no era visto como una criatura de Bardas ${ }^{8}$. Sin embargo, su carácter de laico fue utilizado en su contra en esta ocasión. Antes que él Pablo III (en 688), su tío Tarasio (en 784) y Nicéforo (en 806) habían alcanzado el patriarcado siendo altos funcionarios imperiales, pero lo que entonces había sido aceptado de buen grado ahora provocaba escándalo. Sus enemigos lo presentaban como un arribista "medio heleno" e ironizaban con la promoción de un laico a la condición de patriarca en tan sólo 5 días.

A pesar de que las fuentes ignacianas afirman lo contrario, es verosímil que Ignacio firmara un acta de abdicación, que presentaba la novedad de in- 
cluir condiciones. Y es que Focio habría firmado su obligación de reconocer la dignidad patriarcal a Ignacio y plegarse a su voluntad. En caso contrario, Ignacio volvería a ser el patriarca legítimo?.

Con independencia del precio pagado, la alianza entre las dos facciones, la fociana y la ignaciana, duró poco. El deseo de Focio de incluir a Gregorio Asbestas entre los obispos que lo consagraron fue considerado una provocación ${ }^{10}$. De hecho, su presencia en este acto fue uno de los puntos de la acusación presentada en Roma, donde el caso del arzobispo de Siracusa permanecía pendiente. Con todo, el intento fociano de reunificar la Iglesia bizantina pasaba por ganarse a los simpatizantes del arzobispo de Siracusa y a Gregorio mismo, ya que constituía un vínculo obvio con el difunto patriarca Metodio, del que había sido un muy cercano colaborador ${ }^{11}$.

Progresivamente la situación política se encendió y, a pesar de algunas intervenciones a favor de los ignacianos ${ }^{12}$, Focio fue considerado responsable de una represión policial contra ellos promovida por Bardas y de los malos tratos infligidos al propio Ignacio, trasferido a Hieria, recluido en la prisión de Números y finalmente deportado por mar a Mitilene (Vita Ignatii 513). Los defensores del ex-patriarca afirmaban que Focio era un perjuro e insinuaron que había intentado recuperar el juramento firmado. Por tanto, Ignacio volvía a ser el patriarca legítimo, aunque se encontrase en el exilio ${ }^{13}$.

Frente a esta situación, la única vía que encontró Focio fue convocar un sínodo que excomulgó a Ignacio y suscitó la secesión de una docena de obispos y numerosos hegúmenos, entre ellos, Nicolás de Estudio ${ }^{14}$. El cisma había sido ratificado.

El partido ignaciano tuvo entonces que organizar la resistencia, de la cual muy poco sabemos. Con todo, dentro del epistolario del patriarca Focio ${ }^{15}$ encontramos cuatro misivas enviadas a Bardas al principio de su primer patriarcado en referencia al trato que daba a los ignacianos y sus simpatizantes (epp. 3, 4 y 6). Sobre el trato que hay que dar a los ex-ignacianos no se volverá a preocupar hasta el final de su segundo patriarcado, a juzgar por el testimonio de las epp. 281 y 283, probablemente por la falta de una estructuración firme en el partido ignaciano. Sin embargo, estas últimas cartas no fueron incluidas por Focio en la colección, por lo que no está de más pensar que fueron muchas las misivas referentes a esta cuestión las escritas a lo largo de su vida, lo que incide en la idea de que aunque no estuviese bien articulado sí que existía una oposición ignaciana que amalgamaba a disidentes e ignacianos convencidos. Ahora bien, los objetivos perseguidos con la publicación de sus epístolas al volver del destierro recomendaban la no inclusión de estas piezas, lo que explica la total ausencia de referencias al respecto, salvo los casos, en los que Focio intercede por distintos monjes ignacianos. 
Las epístolas (epp. 3, 4 y 6) dirigidas a Bardas, su principal valedor y hombre fuerte de Miguel III, corroboran la consecución de cierta cohesión interna de la Iglesia bizantina, consiguiendo lavar la imagen de Focio, que se presenta como eficaz intercesor ante los poderes políticos a favor de los seguidores de Ignacio, su antiguo contrincante en la carrera hacia el trono patriarcal.

La ep. 3 se fecha en febrero del año 859, es decir, poco después del exilio de Ignacio y la ascensión de Focio a la dignidad patriarcal el 25 de diciembre de 858. Para entonces ya existía un grupo hostil bien formado en contra de Focio, al que veían como un intruso, que se encontró de lleno con la furia de Bardas, quien -como reza la intitulatio de la ep. 3- ya ostentaba ya

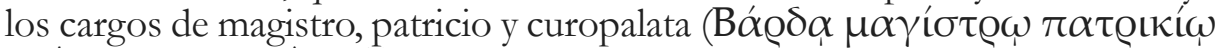

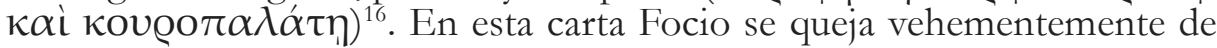
que Bardas maltrata al clero ignaciano, haciendo que incluso algunos mueran

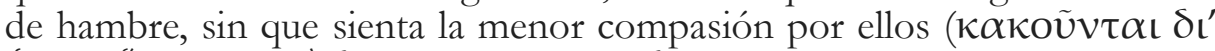

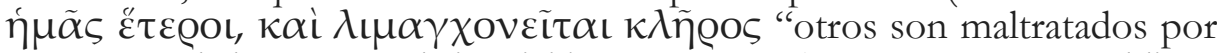
nosotros y el clero muere de inanición" ep. 3, 32-33). Lo peor es que maldicen a Focio por considerarlo responsable de esta situación, ya que Bardas no

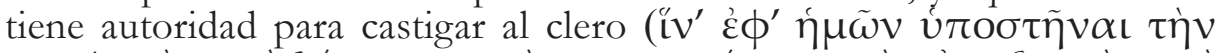

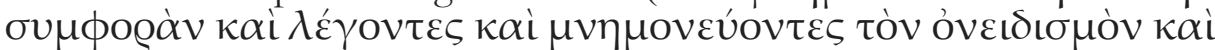

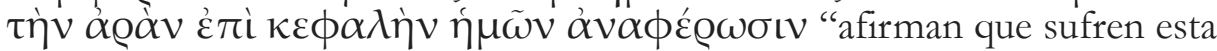
desgracia de parte nuestra y pronuncian reproches lanzando maldiciones sobre nuestra cabeza" ep. 3, 34-35).

En la misma línea están las epp. 4 y 6 en las que intercede ante Bardas por dos ignacianos que han sido castigados con excesiva dureza hasta el extremo de que su vida corre peligro: el asecreta Cristódulo, que se refugió en Santa Sofía tras haber recibido un severo castigo corporal por burlarse del emperador y de su tío Bardas cuando estaba borracho, y el monje Blasio. De hecho, en la ep.6 Focio intercede por los clérigos ignacianos que han sido perseguidos, encarcelados y torturados, y especialmente por Blasio ${ }^{17}$, a quien Bardas mandó cortar la lengua desoyendo las súplicas de Focio.

Las atrocidades cometidas por el curopalata están en sintonía con la crueldad con la que trató al depuesto Ignacio. Tal y como relatan Genesio $(70,67-72,3)$ y Nicetas (Vita Ignatii 520-521), Bardas lo sometió a distintas torturas que casi le cuestan la vida y terminó por ordenar su reclusión en el mausoleo de los Santos Apóstoles. Allí fue encerrado en el sarcófago del emperador iconoclasta Constantino V Coprónimo, contrayendo una terrible disentería que le habría provocado la muerte de no ser por la aparición providencial de un buen hombre.

El resto de la tortura de Ignacio lo conocemos por la crónica del Pseudo Simeón $(667,13-668,2)$, que describe su exilio en la isla de Terebinto, 
en Hieria y en Promoto, donde León Lalacaón le abofeteó rompiéndole las mandíbulas y sacándole dos dientes. Finalmente fue trasladado a la prisión de Números. El envío de Ignacio a Mitilene en agosto de 859 fue acompañado de la dispersión de los metropolitas afines a él por las distintas cárceles del Imperio.

El interés histórico de estas cuatro epístolas dirigidas a Bardas es mucho, entre otras razones porque son nuestra principal vía de conocimiento de la actitud de Focio hacia sus contrarios en los primeros años de su ministerio, así como de una estructuración estable de los ignacianos. Una vez que en abril de 862 Bardas fue asociado al trono imperial en calidad de césar, aumentan de forma considerable las cartas de este patriarca que hacen referencia a la querella fociana. Sin duda alguna, la solución encontrada por Focio de excomulgar en un sínodo a Ignacio apenas un año antes lejos de zanjar el asunto, tan sólo sirvió para radicalizar las posiciones de uno y otro sector, incentivando una lucha interna que marcará el devenir posterior de la Iglesia bizantina durante años.

En la primavera del año 860, Focio se sentía suficientemente asentado en el poder como para despachar las epístolas 288 y 289 en las que comunicaba a sus homólogos (los patriarcas orientales y al papa Nicolás I) su nueva situación al frente del patriarcado capitalino. La disputa a la que dio pie entre Focio y los otros cuatro grandes patriarcas de la cristiandad repercutió inevitablemente en todos los niveles del clero bizantino ${ }^{18}$.

Del sínodo celebrado en la iglesia de los Santos Apóstoles de Constantinopla en el invierno de 860-861 emanó un documento firmado por ciento treinta obispos y los dos legados papales Rodoaldo de Porto y Zacarías de Anagni. Aunque fue destruido por mandato del concilio antifociano de 869, sabemos que en él se omitía la cuestión ignaciana por expreso deseo de Miguel III y Focio. Sin embargo, ésta constituía la principal preocupación de los enviados papales, que consiguieron reexaminar el caso sin necesidad de remitirlo al pontífice romano.

Ignacio fue traído de Mitilene a Terebinto para declarar y se le pidió expresamente que compareciera como un simple monje y no vestido de patriarca, como defendían sus partidarios (Vita Ignatii 517). Los primeros testigos declararon que había sido consagrado patriarca sin una votación previa, por lo que su elevación no era válida. Ignacio primero rehusó compadecer y después negó a los legados la capacidad de enjuiciarle, lo que inclinó la balanza en su contra. Según Nicetas Paflagón, Ignacio fue torturado en la cárcel a fin de obtener de él un acta de renuncia. Para evitar tales humillaciones, se fugó disfrazado de esclavo y se escondió en una isla de la Propóntide ${ }^{19}$.

El recurso a Roma por ambas partes tan sólo sirvió para enquistar aún más el conflicto. El papa Nicolás I, asesorado por el ignaciano Teognosto y 
muy decepcionado con la labor de sus legados, comunicó en la primavera de 862 al emperador Miguel III que seguía considerando a Ignacio como el patriarca legítimo. Ahora la facción disidente se veía reforzada por un apoyo no menor en su lucha contra Focio.

Un sínodo reunido en san Pedro y continuado en san Juan de Letrán en julio-agosto 863 condenó a los legados Rodoaldo y Zacarías por no seguir los dictámenes papales, pero también promulgó seis cánones que privaban a Focio de cualquier dignidad eclesiástica, deponían a Gregorio Asbestas y expulsaban del clero a todos los que habían sido ordenados por Focio. La sede romana reintegró asimismo a los obispos ignacianos y se reservó el derecho de juzgar a aquellos sobre los que todavía pendía alguna acusación ${ }^{20}$, con lo que la situación se polarizó entre los partidarios del patriarca depuesto y aquellos del patriarca vigente.

Durante el primer patriarcado de Focio ya había habido casos de defección de algunos miembros de la facción ignaciana hacia las filas de Focio. Por ejemplo, Sabas, el hegúmeno del monasterio de Pisades ${ }^{21}$. Sabas había sido ignaciano, pero tras arrepentirse y hacer penitencia se unió a Focio. En algún momento llegó al patriarca el rumor de que su arrepentimiento fue fingido y estaba intrigando contra él, como demuestra la ep. 15, escrita a entre abril de 862 y abril de 866 . Después de expresar la tristeza que este hecho le produce, finaliza comparando a Sabas con una oveja leprosa de la que debe ocuparse el buen pastor, en este caso, Focio.

De hecho, es habitual que encontremos alguna mención a los partidarios de Ignacio cuando alude a los acontecimientos más recientes. Así ocurre, por ejemplo, con la descripción que hace del momento posterior a su primera deposición (año 868) en la ep. 191, 47-54. En ella contrapone la situación de los focianos y la de los ignacianos, ahora promovidos a puestos de poder por la jerarquía eclesiástica e imperial, a los que describe como: "aves rapaces y los zorros, si quieres también a los lobos, dragones, panteras y en una palabra a las bestias que se alimentan de hombres, las instala en mansiones brillantes y lujosas y les concede libertad absoluta para hacer lo que quieran, mientras a los discípulos y seguidores del Hijo del hombre no les permite ni tener donde reposar la cabeza ni ningún permiso de nada de lo que es necesario para vivir".

También en la ep. 7 que es utilizada por Focio para reprochar al monje Pablo el que haya abandonado su causa. Finalmente, le anima a arrepentirse y salvar con su ejemplo a los otros que como él han errado. La intitulatio que precede a esta pieza ya da cuenta de la infidelidad que en ella denuncia el pa-

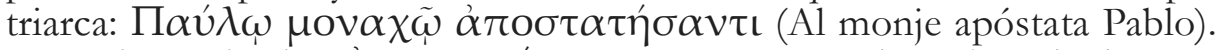
Este mismo término $\alpha \dot{\tau} \operatorname{co\sigma } \tau \alpha \tau \eta ́ \sigma \alpha \nu \tau \iota$ reaparece en el encabezado de otras tres cartas también pertenecientes al primer patriarcado de Focio: epp. 66- 
67 y ep. 104. Estas tres misivas fueron despachadas en distintos momentos

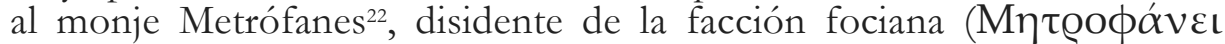
$\mu O v \alpha \chi \tilde{\omega} \alpha \dot{\alpha} \sigma 0 \sigma \tau \alpha \tau \eta \dot{\sigma} \sigma \alpha \nu \tau \iota)$ para conminarlo a que se arrepintiera. La ep. 104 hace referencia a las anteriores llamadas de atención que le había hecho el patriarca y a los castigos que le había acarreado su apostasía (cf. epp. 6667). Dado que hasta ahora el resultado había sido vano, Focio le amenaza con las penas eternas del infierno. Esta advertencia debió de ser mucho más efectiva, sin duda, pues lo siguiente que sabemos es que durante el exilio que siguió a la deposición del patriarca en 867 permaneció fiel a su causa. Así lo atestigua la ep. 149 en la que alaba a Metrófanes por su constancia en la adversidad, que ahora ha inundado todo el orbe de la tierra.

Igualmente la intitulatio de la ep. 175 recoge este vocablo: П $\alpha u ́ \lambda \omega \gamma \varepsilon$ -

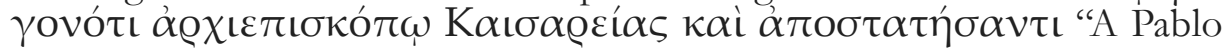
que había sido arzobispo de Cesarea y ahora apóstata". Esta misiva, que quizá fue redactada entre octubre de 869 y el año 870, respondía a una previa de $\mathrm{Pablo}^{23}$ que no conservamos, pero que sabemos que buscaba un intento de reconciliación con Focio. El ex-patriarca responde a Pablo que su apostasía lo ha dejado aislado y que es la gravedad de su acción lo que hace que ni siquiera le saluden los otros monjes.

Una terminología similar a la usada para describir a Pablo y a Metrófanes en sus primeras cartas aparece precediendo otras epístolas de Focio datadas en su primer patriarcado. Así, la intitulatio de la ep. 12 incide en la idea de que el destinatario ha caído en el pecado por haber hecho defección

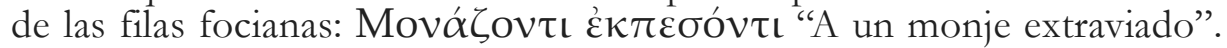
Esta breve carta supone un duro ataque contra un monje que según parece ha abandonado los votos (sc. la facción de nuestro patriarca) e insiste en no

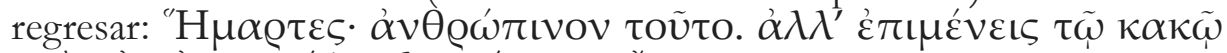

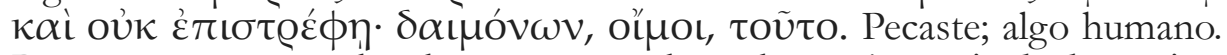
Pero permaneces en el mal y no regresas; lo cual es, jay!, propio de demonios. ep. 12, 2-3.

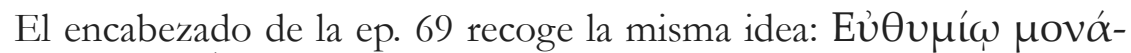

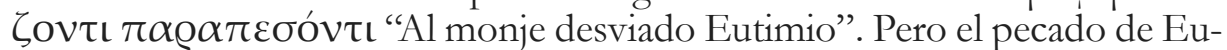
timio $^{24}$ es peor que el del monje al que envía Focio la ep. 12, ya que él además de traicionar a Focio se ha pasado a las filas de Ignacio y actúa contra sus antiguos correligionarios. No debe extrañarnos pues que en él vea Focio un preludio del Anticristo en la ep. 69.

El último caso en el que el delito del corresponsal aparece señalado

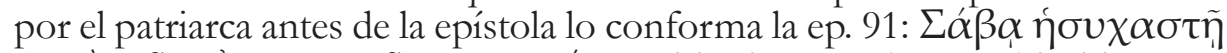
$\mu \varepsilon \tau \dot{\alpha} \tau \tilde{\omega} \nu \alpha \dot{\alpha} \tau O \sigma \tau \alpha \tau \tilde{\omega} \nu \gamma \varepsilon \gamma$ ovó $\tau ا$ "Al hesicasta Sabas establecido entre los apóstatas". Se lamenta de que Sabas ${ }^{25}$, que antes daba la impresión de ser amigo suyo, haya pasado ahora al grupo de sus enemigos y siempre actúe en 
su contra.

En el mismo tono a finales de su primer patriarcado (entre mayo 866 y septiembre 867) Focio escribió al monje hesicasta Atanasio (ep. 20) reconociendo agradecido la importancia que su papel como mediador había tenido en el arrepentimiento de un ignaciano. Se trataba del anciano obispo de Eriste $^{26}$, que se había separado de los cismáticos tras darse cuenta de su engaño y con gran contricción había pedido ser aceptado entre los partidarios

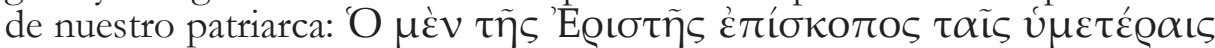

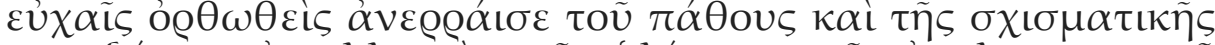

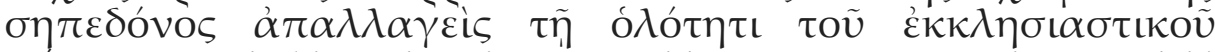
$\sigma \omega \mu \alpha \tau o \varsigma$. "El obispo de Eriste, corregido por vuestras oraciones, volvió tras ser liberado del sentimiento y de la putrefacción cismática por la entereza del cuerpo eclesiástico.” Ep. 20, 2-4.

Con la llegada al poder del emperador Basilio I en 867, Ignacio recuperó la cátedra patriarcal y las tornas se invirtieron. A partir de ese momento, Focio lejos de escribir a los ignacianos reserva sus cartas para aquellos que han estado vinculados a él en el pasado, de tal forma que encontramos algunas epístolas en las que suele atacar a los que le han traicionado dejando de ser focianos.

De acuerdo con DvORNIK la recién estrenada misericordia de Basilio había llevado a algunos focianos a albergar la esperanza de un pacto con los ignacianos, ahora en el poder (DVORNIK 1948: 163). Sin embargo, en distintas misivas Focio les advierte del engaño que se esconde tras esta oferta y desenmascara a los ignacianos, que son identificados con los herejes por medio

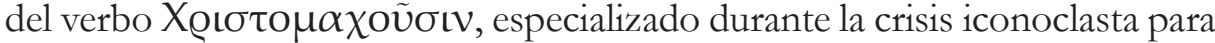
definir a los perseguidores de las imágenes.

Comprendiendo la extrema gravedad que conllevaba entonces la pertenencia al partido ignaciano es mucho más fácil entender la razón del gran número de cartas en las que censura la infidelidad de sus hombres y los múltiples matices emocionales que ésta tiene. Al fin y al cabo, con cada defección hacia las filas contrarias Focio no sólo perdía un partidario, sino que asistía impotente a la condenación de un alma, lo que explica las encendidas palabras del patriarca en esta clase de correspondencia. Precisamente una justificación de esta actitud viene recogida en la ep. 198 que mandó a su buen amigo el metropolita de Cícico Anfíloco. Podemos reconstruir la escena con gran facilidad: Focio habría reconvenido con gran dureza a un amigo común de lealtad discutible, quien habría conseguido que Anfíloco mediara ante su líder. Sin embargo, el patriarca resulta implacable y tras poner el acento en la responsabilidad del receptor de sus amonestaciones, le hace notar al metropolita que de no seguir ese amigo su consejo podría sufrir algo peor (la pena de muerte). 
Desde esta misma perspectiva protectora debemos entender también la ep. 45, destinada al logoteta de Madiam León, en la que lamenta con amargura su traición. Dice Focio que los amigos son útiles en época de necesidad, y aun cuando no cumplen con sus obligaciones también lo son porque demuestran que fueron injustamente queridos por los amigos ahora traicionados, que imitaban al Padre. Si, según dice el rumor, León era un falso amigo, no es necesario que Focio le odie, basta con que él se atenga al juicio venidero.

Varias son las epístolas en las que el patriarca conmina al metropolita de Laodicea a no caer en la traición (epp. 41, 71-72, 140-141, 194). Pese a todo, ninguna consiguió garantizar la lealtad de este metropolita, como tampoco lo hizo la ep. 88, escrita poco antes del fatal desenlace que tuvo para

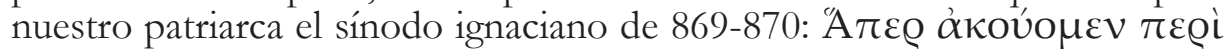

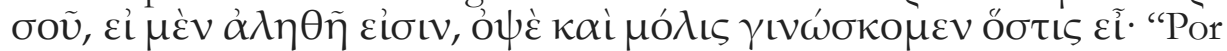
lo que oímos acerca de ti -si es cierto-, aunque demasiado tarde, acabamos de conocer quién eres." Ep. 88, 2-3.

De hecho, el día 7 de octubre del año 869 Teodoro hiciera defección pública hacia el partido ignaciano ${ }^{27}$. Las nefastas consecuencias que estos acontecimientos tuvieron para Focio ya nos son conocidas, por lo que podemos fácilmente comprender el sentimiento de culpabilidad que desarrolló el metropolita de Laodicea y testimonian las epp. 171, 251 y 252.

Los esfuerzos focianos por recuperar a Teodoro fueron vanos. Además, la diócesis de Laodicea pasó a estar dirigida por Pablo, que también desertó, y fue sustituido por Simeón, que era el que ostentaba este cargo en el concilio fociano de 879-880.

Conservamos una pieza dirigida al sustituto de Teodoro como metropolita de Laodicea Pablo (ep. 222) en la que se duele por su deserción. Fechada entre 868 y 872, en ella ataca con dureza a Pablo no sólo por su traición, sino porque su culpa es doble al haber incitado a otro a hacer lo mismo. Así pues, debe ser castigado por su acción, y más por haber incumplido el juramento dado a Focio. Probablemente los acontecimientos referidos tuvieran lugar en el sínodo ignaciano de 869 en el que muchos obispos focianos hubieron de pronunciarse en contra de su anterior líder y terminaron por firmar el acta que anatematizó a Focio. La nueva situación de gran debilidad en la que quedaba el ex-patriarca (excomulgado y desterrado) explicaría el final de la epístola, en la que después de semejantes declaraciones consuela a Pablo al asegurarle que por esta vez el castigo se limita a una sim-

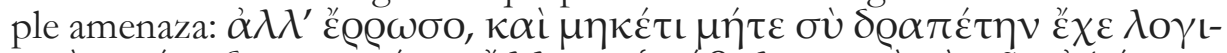

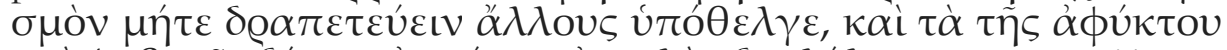

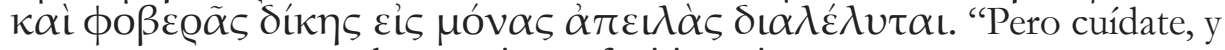
no tengas nunca un planteamiento fugitivo ni engatuses a otros para que 
huyan, y la realidad de una pena inevitable terrible está disipada en simples amenazas." ep. 222, 12-14.

El sínodo ignaciano de 869 fue la prueba de fuego para el partido fociano. Dispersos y privados de líder, los partidarios de Focio tuvieron que ver cómo su gran enemigo recuperaba el trono patriarcal y disponía de ellos con libertad absoluta. La necesidad de alcanzar un consenso mayoritario ante los legados papales hizo que muchos de los focianos que no habían comenzado a apoyar públicamente a Ignacio fueran presionados para conseguir su adhesión a la condena del ex-patriarca. Por propia voluntad o por mero instinto de supervivencia, la facción ignaciana recibió nuevos miembros de las filas focianas. La noticia de estos nuevos ignacianos nos ha llegado principalmente a través de las epístolas de Focio. Tal es el caso de la ep. 136 que tenía por destinatario al diácono y orfanotrofo Jorge. En ella le censura por haber entregado las actas del sínodo fociano de 867 a los legados del Papa para que las quemaran ${ }^{28}$. Un juicio debe examinar la intención y no sólo el resultado de una acción. Jorge se ha perjudicado a sí mismo con su actuación.

Extrema fue la posición de algunos seglares asentados en Constantinopla, quienes tras la condena de Focio no sólo se pasaron del sector fociano al ignaciano, sino que incluso atentaron contra la vida de su anterior dirigente espiritual. Uno de ellos fue el patricio Manuel, que de acuerdo con las actas conciliares había asistido junto a otros nobles al sínodo antifociano de 869 por mandato imperial ${ }^{29}$. Con el fin de censurar su traición e intentar frenar los planes de Manuel, entre octubre de 867 y el año 871, Focio le envió la ep. 226: según el patriarca, el ojo de Dios ve cuanto Manuel trama para sacarlo de entre los vivos por la fuerza, lo que le lleva a recordarle que asesino es quien prepara una muerte, aunque no manche con sangre su espada. Si no depone su intento no podrá a evitar el juicio al que se enfrentará lloroso y apenado, aún cuando Focio no desea que se vea en tal situación.

Un contenido similar tienen las epp. 5 y 124, dirigidas al protospadario y estratego del Peloponeso Juan ${ }^{30}$ entre febrero y agosto del año 859 y al protospadario Teodoto ${ }^{31}$ respectivamente. En ellas les pregunta por qué traicionándole han cambiado lo eterno por lo caduco y el cielo por el infierno. Planteamiento este que dentro del epistolario de Focio resulta extrapolable a todos los miembros del partido ignaciano independientemente de su mayor o menor organización una vez que carecieron de líder. 


\section{BIBLIOGRAFÍA}

Bury, J. B., A History of the Later Roman Empire from the Fall of Irene to the Accession of Basil I (802-867), London, 1912.

DArrouzès, J., "Le Patriarche Méthode contre les Iconoclastes et les Stoudites", REB 45 (1987) pp. 15-57.

Dobschütz, E. VOn, "Methodius und die Studiten", Byz 18 (1908) pp. 41-105.

Dvornik, F., The Photian Schism. History and Legend, Cambridge, 1948 [reimp. 1970].

Dvornik, F., "The Patriarch Photius in the Light of recent Research", en Berichte zum XI. Intern. Byzantinistenkongress, München, 1958, vol. III/2, pp. 1-56 [reimpr. en Photian and Byrantine Ecclesiastical Studies, Londres, Variorum 1974, capítulo VI].

Grumel, V., 'L'encyclique de Photius aux Orientaux et les patriarches de Constantinople Sisinnius II et Sergius II", EO 34 (1935) pp. 129-138.

Grumel, V., "La genèse du schisme photien. La succession d'Ignace", en Atti del V Congresso Internazionale degli Studi Bizantini, RSBN 5 (1939) pp. 179-184.

Grumel, V., "Le schisme de Grégoire de Syracuse”, EO 39 (1940-42) pp. 257-267.

Grumel, V., Les regestes des actes du Patriarcat de Constantinople. Vol. I. Les Actes des Patriarches. Fasc. II et III: Les Regestes de 715 a 1206, Paris, $1989^{2}$.

Guilland, R., "Curopalate”, Byzantina 2 (1970) pp. 187-249 [reimp. en ID., Titres et fonctions de l'Empire byrantin, Londres, 1976].

Hergenröther, J., Photius von Konstantinopel: sein Leben, seine Schriften und das griechische Schisma nach handschriftlichen und gedruncketen Quellen, 3 vols., Regensburg, 1869 [reimpr. Darmstadt, 1966].

JANIN, R., Les églises et les monastères des grands centres byzantins Bitbynie, Helllespont, Latros, Galèsios, Trébizonde, Athènes, Thessalonique), Paris, 1975.

Karlin-Hayter, P., "Gregory of Siracusa, Ignatios und Photios", en Bryer, A. y Herrin, J. (eds.), Iconoclasm. Papers Given at the Ninth Spring Symposium of Byzantine Studies (University of Birmingham, March 1975), Birmingham, 1977 , pp. 141-145.

Laourdas, B. y Westerink, L. G., Photii patriarchae constantinopolitani Epistulae et Amphilochia, vols. 1-3, Leipzig, Teubner, 1983-1987.

Lilie, R.-J., et al., Prosopographie der mittelbyzantinischen Zeit. 1-, Berlin 
1999- [=PmbZ].

MANSI, G. D., Sacrorum conciliorum nova et amplissima collectio, FlorenciaVenecia, 1759-1798.

STEPhanou, P., "Les débuts de la querelle photienne vus de Rome et de Byzance”, OCP 18 (1952) pp. 270-80.

StePhanou, P., "La violation du compromis entre Photius et les Ignatiens”, OCP 21 (1955) pp. 291-307.

\section{NOTAS}

${ }^{1}$ Grumel 1989: 79 (n. 435); DOBSCHÜTZ 1908; DARROUZÈs 1987.

2 Bibliotheca Sanctorum IX: 393; sub voce Metodio I. A propósito de la figura de Gregorio Asbestas, cf. PmbZ \# 2480.

${ }^{3}$ DVORNIK 1948: 36-38.

${ }^{4}$ GRUMEL 1935; KARLIN-HAYTER 1977.

${ }^{5}$ GRUMEL 1989: 88 (n. 445), que data este acontecimiento a finales del año 847-848; GRUMEL 1940-42.

${ }^{6}$ DVORNIK 1958: 11 y ss.

${ }^{7}$ Vid. GRUMEL 1939.

${ }^{8}$ Muy elocuentes resultan las palabras de DvORNIK, que explica los motivos por los que Focio fue elegido como sucesor de Ignacio del siguiente modo:

"He seemed acceptable to both parties. As an intellectual He naturally sympathized with the moderates, but, up to then, he owed all his promotions, the professorship at the University, the post of First secretary of the Chancery and the membership in the Senate, to Theoctistus and to Theodora. His last public function, the embassy to the Arabs, had been entrusted to him by Theoctistus and Theodora. The marriage of his brother to Theodora's sister seemed also to have tightened the relationship of Photius' family with Theodora. Moreover, He could not be blamed for any partisanship in the overthrow for Theoctistus and Theodora, for it had happened while He was on his mission to the Arabs. As head of Imperial Chancery, Photius must have shown an extraordinary talent or practical administration. He was not only a fervent iconodule, but also well versed in theological lore." DVORNIK 1958: 12-13.

${ }^{9}$ GRUMEL 1989: 96 (n. 456); STEPHANOU 1955.

${ }^{10}$ A él le remitió, entre otras, las epístolas 112 y 257 recogidas en su colección de cartas; la primera de ellas corresponde al inicio de su destierro, mientras que la segunda se data hacia el año 879 .

${ }^{11}$ KARLIN-HAYTER 1977.

${ }^{12}$ GRUMEL 1989: nn. 459, 460, 463.

${ }^{13}$ STEPHANOU 1955.

${ }^{14}$ GRUMEL 1989: $96-99$ (nn. 458, 461, 462).

${ }^{15}$ Seguimos en todo momento la numeración establecida en la reciente edición de LAOUR- 
DAS-WESTERINK 1983-1987.

${ }^{16}$ La misma intitulatio encontramos precediendo a la ep. 6. El nombramiento de Bardas como curopalata fue acompañado del de su hijo Antígono como doméstico de las escolas, vid. BURY 1912: 161. Sobre las funciones y prerrogativas de este cargo, cf. GUILLAND 1970; sobre el ceremonial que acompañaba la promoción a curopalata, cf. De ceremoniis I, 229-231.

${ }^{17}$ Nicetas (Vita Ignatii 513C) nos informa de que se trataba del cartofilaco de Santa Sofía, uno de los amigos del depuesto Ignacio, que por estas fechas acababa de ser deportado a Mitilene.

${ }^{18}$ STEPHANOU 1952.

${ }^{19}$ Vita Ignatii: 521-525. Un terrible seísmo sacudió Constantinopla durante cuarenta días, hecho que es considerado por el biógrafo el castigo de Dios por la injusticia cometida contra su siervo Ignacio. Bardas se habría quedado tan impresionado que permitió la salida de prisión del ex-patriarca y garantizó su regreso al convento.

${ }^{20}$ Del contenido de este sínodo nos informa el propio Nicolás I por medio de una epístola que envió el 13 de noviembre de 866 a los obispos y a todo el clero de la diócesis constantinopolitana. Vid. MGH, Ep. VI: 521-533.

${ }^{21}$ Se trata de un cenobio asentado en la zona bitinia del monte Olimpo, a una altura de 1320 metros sobre el nivel del mar, vid. JANIN 1975: 172-174.

${ }^{22}$ De acuerdo con HeRGENRÖTHER 1869, vol I: 647; vol II: 45 y 724, se trataría del Metrófanes que llegó junto con Basilio, Zósima y otros a Constantinopla para implorar la ayuda de Focio contra el papa Nicolás I (cf. ep. 2, 327-330). Por la intitulatio de la ep. 149 sabemos

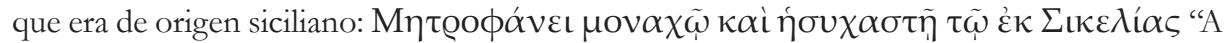
Metrofanes, monje y hesicasta de Sicilia".

${ }^{23}$ Ordenado por Focio, Pablo estuvo presente en el sínodo de 861 y ayudó a condenar a Ignacio. Sin embargo, el propio Ignacio afirma en una carta destinada al papa Nicolás que al final se negó a suscribir las acusaciones (MANSI 16: 49CD), lo que hizo que fuera sustituido por Eusquemón.

${ }^{24}$ A lo que parece, no debemos identificar a este monje Eutimio con el hegúmeno ignaciano al que Focio persiguió con dureza según narra Pseudo-Simeón 672. Vid. HERGENRÖTHER 1869, vol II: 732-733.

${ }^{25}$ Según HERGENRÖTHER 1869, vol II: 196, se trata del mismo Sabas, presbítero y hesicasta, al que dedica Focio dos cartas de contenidos teológico (epp. 176-177 = Amph. 95-96). Sin embargo, como bien señala WESTERINK en su edición el nombre de Sabas era de uso muy frecuente entre los monjes de la época.

${ }^{26}$ Población desconocida para nosotros, si bien sabemos que pertenecía a la diócesis de Nicomedia. De acuerdo con JANIN 1975: 129-130 se asentaría a los pies del monte Olimpo bitinio, en la región de Atroa.

Dentro de la diócesis de Nicomedia se asentaban las comunidades monásticas del monte Olimpo, claramente partidarias de Ignacio (DVORNIK 1948: 65-68). Asimismo, en esta zona ejercían su ministerio figuras como el hesicasta Anastasio, cuya virtud en territorio hostil deja patente Focio en la ep. 93 al compararlo con la palmera que crece en tierras saladas (vid. et. epp. 20, 26, 27, 93 y 212) o el obstinado obispo de Lofos Ignacio que nunca debió de ser un convencido fociano (cf. epp. 23 y 70). 
${ }^{27}$ No sabemos hasta qué punto por deseo expreso u obligado por las circunstancias. Sea como fuere, Teodoro fue uno de los obispos focianos que en el concilio antifociano de 869870 reconocieron su error, siendo reconocidos en comunión con la Iglesia por Ignacio, cf. MANSI 16: 37-42; 320-321.

${ }^{28}$ Los acontecimientos tuvieron lugar el día 5 de noviembre de 869, vid. MANSI 16: 136AB. ${ }^{29}$ MANSI 16: 18B; 309D. La identificación de este Manuel es compleja: tal vez se trate del patricio Manuel que desempeñaba el cargo de logoteta del dromo y recibió hacia 870 la carta del metropolita de Esmirna Metrófanes en la que se describen las razones por las que Focio había sido apartado de la sede patriarcal. Tal vez, incluso, pueda tratarse del patricio Manuel que aparece en la Vita de Nicolás de Estudio (PG 105, 916B-D) asistiendo a la sanación milagrosa de su mujer por el santo.

${ }^{30}$ El códice $\mathbf{G}$ nos ha conservado su apelativo: Coxes; vid. PmbZ \# 3310. Para el mes de abril del año 861 ya había alcanzado el título de patricio, puesto que este Juan fue quien, por orden imperial, trajo a Ignacio ante el sínodo para que declarara en una de las sesiones vestido de simple monje, vid. Vita Ignatii 517D.

${ }^{31}$ Por la intitulatio de la ep. 147 sabemos que desempeñaba su cargo en Lalaconia: $\Theta \varepsilon o \delta o ́ t \omega$

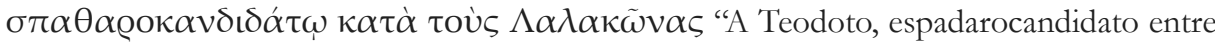
los Lalacones". Desconocemos por completo cualquier otro dato sobre su vida, cf. PmbZ \# 7970. 